\title{
WHEN IS AN ASYMMETRIC PLANT-POLLINATOR RELATIONSHIP SYMMETRICAL?
}

\author{
PAVEL KINDLMANN ${ }^{1}$ and DAVID L. ROBERTS ${ }^{2, *}$ \\ ${ }^{1}$ Department of Biodiversity Research, Global Change Research Centre AS CR, Na Sádkách 7, České Budějovice, Czech Republic \\ and Institute for Environmetal Studies, Faculty of Science, Charles University, Benátská 2, Prague, Czech Republic. \\ E-mail: pavel.kindlmann@centrum.cz \\ ${ }^{2}$ Royal Botanic Gardens, Kew, Richmond, Surrey, TW9 3AB, UK. Tel. +44 (0)20 8332 5291; Fax +44 (0)20 83325278 \\ ${ }^{\star}$ Corresponding author: d.roberts@kew.org
}

\begin{abstract}
The Orchidaceae is a highly evolved, pollinator orientated family with some of the most specialized pollination systems. It has been suggested that plant specialization should be considered along with the degree of specialization of the mutualist partners and that both sides of the mutualistic interaction need to be evaluated to gain insights into the response of species to habitat fragmentation. Here we raise the question of reward systems, in particular, species that are pollinated through deception. The model is applied to two specialist plant genera with different means of deception, food and sexual, and compare the levels of decline of the two genera throughout Europe. We show that there is a highly significant difference between Dactylorhiza (food deceptive) and Ophrys (sexually deceptive) in the rate of decline, with Ophrys suffering much stronger decline consistently across Europe.
\end{abstract}

Keywords: Dactylorhiza, deception, habitat fragmentation, Ophrys, Orchidaceae

\section{Introduction}

Intuitively, one would expect that habitat fragmentation would have a greater effect on the reproductive success of pollination specialist plants than generalist due to changes in pollinator communities. However, studies have suggested that this may not be the case, with no difference being recorded between the reproductive success of generalist and specialists plant species (Aizen et al. 2002; Vázquez and Simberloff 2002). Ashworth et al. (2004) suggested that plant specialization needs to be considered along with the degree of specialization of the mutualist partners and that both sides of the mutualistic interaction need to be evaluated.

There is a trend in the Orchidaceae towards a reduction in the number of pollinator species per orchid species resulting in increased specialization (Tremblay 1992). Orchid-pollinator interactions are often considered to be asymmetrical, with the orchid relying far more on its pollinator than the pollinator on the orchid. As Nilsson (1992) stated "interaction between two such unequally interdependent organisms inevitably results in the first being pushed around genetically by the second: pollinator traits govern any floral evolutionary trend." An example of the asymmetrical orchid-pollinator relationship is the hawkmoth (Panogena lingens), which was found to pollinate at least 5 species of long-spurred angraecoid orchids (Nilsson et al. 1987). Such behaviour has also recently been recorded in other species of angraecoid orchids (Martins and Johnson 2007). In these cases the pollinator may only have adapted to access the nectar resource of long spurred orchids (Nilsson 1988). However, approximately one-third of orchids have evolved mechanisms of deceit, where the pollinator receives no reward (van der Pijl and Dodson 1966; Ackerman 1984). In this situation, since there is no reward, the pollinator receives no benefits.

Ashworth et al. (2004) considered mutualistic plantpollinator interactions. However, in the case of species that utilize deception as pollination strategy the relationship cannot be considered mutualistic. Rather the relation may be considered parasitic since the pollinator does not receive a reward and therefore the relationship on the side of the pollinator may be neutral or even negative (Wong and Schiestl 2002).

Under asymmetric conditions the model (Ashworth et al. 2004) suggests that a generalist plant may have many different specialist and generalist pollinators whereas a specialist is likely to have few pollinators but those are expected to be generalists. The latter would seem to fit situations seen in orchid-pollinator interactions, particularly in the case of deceptive orchids, since how could a specialist pollinator (i.e. those that rely on one or a few plant taxa) be attracted and evolve to a deceptive orchid when there is no fitness benefit? This is seen in the food deceptive genus Dactylorhiza that relies often on bees to facilitate pollination while the bees visit numerous rewarding species (van der Cingel 1995).

However, in species that utilize sexual deception (pseudocopulation), such as Ophrys, the relationship is actually symmetrical with both sides being specialists. The orchid relies on one or few insect pollinators that visit the orchid for perceived sexual benefit (i.e. reproduction). The pollinator, therefore, is in fact a specialist since it is only interested in sexual liaisons with females of the same species; that is not to say that its foraging behaviour is not generalist. 


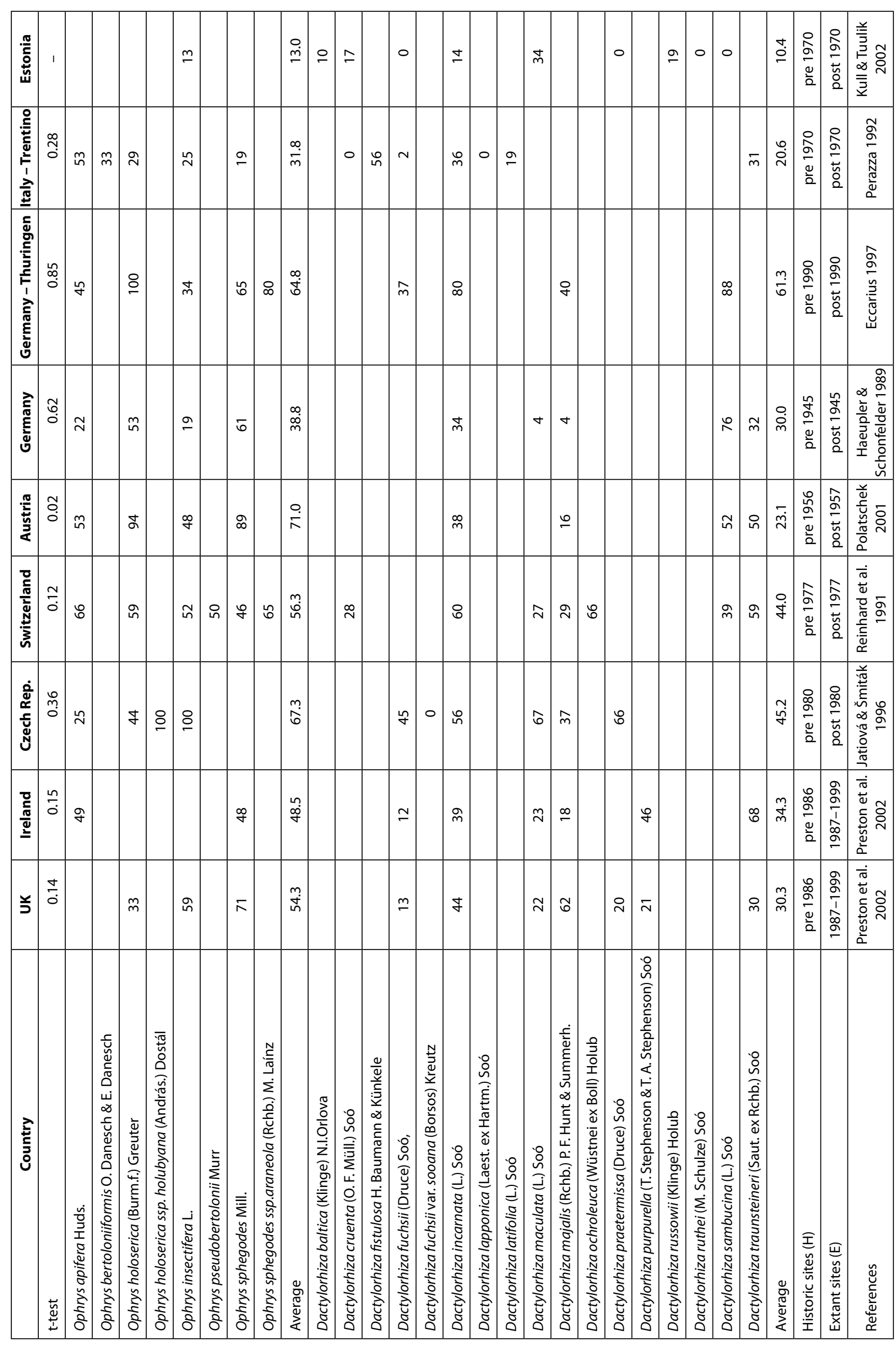


If the model of Ashworth et al. (2004) holds, then we would expect sexually deceptive species to be more susceptible to habitat fragmentation than food deceptive species. Here we compare the decline of the food deceptive genus, Dactylorhiza, with that of the sexual deceptive genus, Ophrys, throughout Europe.

As an alternative hypothesis, one could expect that the rate of decline of sites of different orchid species within a genus would be negatively correlated with the number their pollinator species.

\section{Methods}

We used available data from regional flora atlases on the numbers of historic vs. extant sites from nine European countries or parts thereof, containing information on at least one species of Dactylorhiza and Ophrys. For each country, the rate of decline was calculated as the ratio of historic sites ( $\mathrm{H}$ in Table 1 ) to that of all sites ever recorded $(\mathrm{E}+\mathrm{H}$ in Table 1$)$. We then compared the rate of decline in these two genera, using a two-factor ANOVA and a series of two-sample two-tailed t-tests assuming unequal variances. We correlated, using Pearson's correlation coefficient, the numbers of pollinator species with the rates of decline of sites for different Ophrys species. Only countries or regions with at least 4 Ophrys species were considered (Switzerland, Austria, Thüringen and Italy) using pollinator data from van der Cingel (1995).

\section{Results}

Table 2 shows that there is a highly significant difference between Dactylorhiza and Ophrys in the rate of decline, with the latter genus suffering much stronger decline. The t-tests (Table 1), however, show that when individual countries are considered, this difference is statistically significant only for Austria. Further, if Bonferroni correction is applied this result becomes not significant $(p=0.17)$. This means that it is the consistently stronger decline of Ophrys across Europe that is responsible for the significant difference (Fig. 1).

Table 2 Two-factor ANOVA without replication with factors Genus and Country and rate of decline as the response variable.

\begin{tabular}{|l|r|r|r|r|r|c|}
\hline Source of Variation & \multicolumn{1}{c|}{ SS } & df & \multicolumn{1}{c|}{ MS } & F & P-value & F crit \\
\hline Genus & 1148 & 1 & 1148 & 13.94 & 0.006 & 5.32 \\
\hline Country & 3941 & 8 & 493 & 5.98 & 0.010 & 3.44 \\
\hline Error & 659 & 8 & 82 & & & \\
\hline Total & 5749 & 17 & & & & \\
\hline
\end{tabular}

Correlation coefficients between the numbers of pollinator species and the rates of decline of sites for different

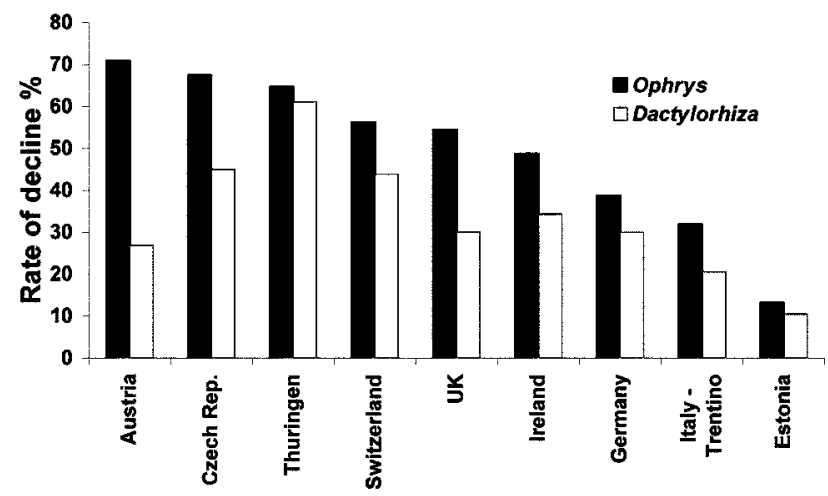

Fig. 1 Average rate of decline for two genera of terrestrial orchids, Dactylorhiza and Ophrys, in 9 European countries or parts thereof.

Ophrys species were were all positive and not significant $(p>0.05)-r=0.72$ for Switzerland, $r=0.26$ for Austria, $\mathrm{r}=0.49$ for Thüringen and $\mathrm{r}=0.64$ for Italy.

\section{Discussion}

These results indicate that species that utilize sexual deception are more prone to extinction than food deceptive species, that is to say specialist plants with symmetri$\mathrm{cal}$ interactions are more sensitive than those with asymmetric interactions. Ashworth et al. (2004) are therefore correct in stating that "plant specialization cannot be considered in isolation from the degree of specialization of the mutualist partners" and that "evaluation of both sides of the mutualistic interaction will yield insights into the mechanisms behind species' responses to habitat fragmentation". However, the reward is the tangible benefit pollinators receive, although they are usually attracted to the flower in the first place through advertisement (Proctor et al. 1996). Therefore, the plant-pollinator relationships cannot be considered in isolation from the reward system even if the reward is from an unrelated source, such as in the case of sexual deception.

The outcome above is not affected by the length of the time periods from the countries studied, as this only affects the magnitude of the differences between results for the two genera, not the consistently larger decline in Ophrys. The longer the periods considered, the larger the difference.

The alternative hypothesis was not supported by our data. The number of pollinator species per orchid species did not significantly affect the rate of decline of orchid sites within the genus Ophrys. This again leaves us with the hypothesis of Ashworth et al. (2004) as the only plausible option. It should be noted that, while the underlying assumption of the paper is that reward system is the main difference between the genera, other possible generic differences such as in demography, fruit set, mycorrhizal specificity, clonality, etc, could contribute towards the different levels of decline seen. No evidence is 
available to suggest this. Further, most differences such as in fruiting success, seed production, breeding system are indirectly, if not directly, related to the reward system (Cozzolino and Widmer 2005; Tremblay et al. 2005; Jersáková et al. 2006).

\section{Conclusions}

Ecosystem decay has led to a "pollination crisis" caused by the disruption in pollination systems. The cause of the crisis, human activity, is widespread and it is therefore likely that pollination disruption is also widespread (Buchmann and Nabham 1996). Not surprisingly then that there is a consistently stronger decline of Ophrys across Europe. However, when individual countries are considered, this difference is statistically significant only for Austria, although this becomes non-significant when Bonferroni correction is applied, suggesting that the cause is widespread, consistent and crosses international boundaries. Two such causes may be climate change or intensification of agriculture.

\section{Acknowledgements}

This research was supported by the grants No. LC06073 and MSM 6007665801 of the Czech Ministry of Education. We thank Iva Schödelbauerová for her help in compiling part of the data.

\section{REFERENCES}

Ackerman JD (1984) Pollination of tropical and temperate orchids. In: Tan KW (ed.) Proceedings of the 11th World Orchid Conference. American Orchid Society, Miami, Florida, pp 98-101.

Aizen MA, Ashworth L, Galetto L (2002) Reproductive success in fragmented habitats: do compatibility systems and pollination specialization matter? J Veg Sci 13: 885-892.

Ashworth L, Aguilar R, Galetto L, Aizen MA (2004) Why do pollination generalist and specialist plant species show similar reproductive susceptibility to habitat fragmentation. J Ecol 92: 717-719.

Buchmann SL, Nabham GP (1996) The forgotten pollinators. Island Press, Washington, DC.

Cozzolino S, Widmer A (2005) Orchid diversity: an evolutionary consequence of deception? Trends Ecol Evol 20: 487-494.
Eccarius W (1997) Orchideen in Thüringen. Uhlstädt: Arbeitskreis Heimische Orchideen.

Haeupler H, Schönfelder P (1989) Atlas der Farn- und Blütenpflanzen der Bundesrepublik Deutschland. Stuttgart, Eugen Ulmer.

Jatiová M, Šmiták J (1996) Rozšíření a ochrana orchidejí na Moravě a ve Slezsku. Arca JiMfa.

Jersáková J, Johnson SD, Kindlmann P (2006) Mechanisms and evolution of deceptive pollination in orchids. Biol Rev 81: 219-235.

Kreutz CAJ, Dekker H (2000) De Orchideeën van Nederland. Raalte and Landgraaf.

Kull T, Tuulik T (2002) Kodumaa Käpalised. Eesti Orchideekaitse Klubi.

Martins DJ, Johnson SD (2007) Hawkmoth pollination of aerangoid orchids in Kenya, with special reference to nectar sugar concentration gradients in the floral spurs. Am J Bot 94: 650-659.

Nilsson LA (1988) The evolution of flowers with deep corolla tubes. Nature 334: 147-149.

Nilsson LA (1992) Orchid pollination biology. Trends Ecol Evol 7: 255-259.

Nilsson LA, Jonsson L, Ralison L, Randrianjohany E (1987) Angraecoid orchids and hawkmoths in central Madagascar: specialized pollination systems and generalist foragers. Biotropica 19: 310-318.

Perazza G (1992) Orchidee spontanee in Trentino Alto Adige, riconoscimento e diffusione. Manfrini Editori.

Polatschek A (2001) Flora von Nordtirol, Osttirol und Vorarlberg, Band 5. Tiroler Landesmuseum Ferdinandeum.

Preston CD, Peaman DA, Dines TD (eds) (2002) New Atlas of the British and Irish Flora. Oxford Univ. Press.

Proctor M, Yeo P, Lack A (1996) The natural history of pollination. Harper Collins Publishers.

Reinhard HR, Gölz P, Peter R, Wildermuth H (1991) Die Orchideen der Schweiz und angrenzender Gebiete. Fotorotar AG, Druck + Verlag.

Tremblay RL (1992) Trends in the pollination ecology of the Orchidaceae: evolution and systematics. Can J Bot 70: 642-650.

Tremblay RL, Ackerman JD, Zimmerman JK, Calvo RN (2005) Variation in sexual reproduction in orchids and its evolutionary consequences: a spasmodic journey to diversification. Biol J Linn Soc 84: 1-54.

van der Cingel NA (1995) An Atlas of Orchid Pollination: European orchids. A.A. Balkema, Rotterdam.

van der Pijl L, Dodson CH (1966) Orchid flowers: their pollination and evolution. Univ. of Miami Press, Coral Gables, Florida.

Vázquez DP, Simberloff D (2002) Ecological specialization and susceptibility to disturbance: conjectures and refutations. Am Nat 77: 1043-1060.

Wong BBM, Schiestl FP (2002) How an orchid harms its pollinator. Philos T Roy Soc B 269: 1529-1532. 